\title{
LA ESPIRITUALIDAD Y LA RELIGIÓN EN EL TRABAJO
}

\author{
Por: \\ Guillermo S. Edelberg $\mathrm{DBA}$ *
}

\section{LA ESPIRITUALIDAD EN EL TRABAJO}

E

I Dr. Robert W. Mullins, apreciado colega fallecido hace unos años, era el director del Programa Máster en Administración de Empresas del INCAE a mi llegada a esta casa de estudios. En una oportunidad, poco antes de la graduación de un nuevo grupo de estudiantes, colocó una nota de despedida en una vitrina. La leí y me pareció? y sigue pareciendo? muy acertada en su contenido y brevedad. Próximos a ingresar al frío mundo real (as you enter the cold, real world), les deseaba suerte y éxito en sus carreras profesionales. En la actualidad, cuando leo u oigo acerca de la espiritualidad en el trabajo (spirituality in the workplace), me vienen a la memoria las palabras del Dr. Mullins porque ambas expresiones aparentan contradecirse. Si se tolera la espiritualidad en el frío mundo real ¿no será que el saludo del Dr. Mullins es menos acertado de lo que pensaba?

\section{¿Qué se entiende por "espiritualidad}

en el trabajo"?

La pregunta no es fácil de contestar. Las res-puestas parten tanto de un punto de vista religioso como de otro que evita toda referencia a una religión. Sumado a esto están las opiniones que señalan que el lugar de la espiritualidad se halla afuera de la empresa y las que dicen que se trata de un tema viejo con un nombre nuevo o una nueva moda que es poco más que el sensitivity training de los años 50.

Dada la variedad de definiciones de espiritualidad en el trabajo, distintos autores optan por presentar las que han podido identificar; por ejemplo (Competitiveness Review. Indiana: 2004):

- El sentimiento básico de estar conectado con la totalidad de uno mismo, con otros y con el universo.

\footnotetext{
* Profesor Emérito INCAE Business Scholl.

Este artículo fue entregado el 17 de mayo de 2006 y su publicación aprobada por el Comité Editorial el 25 de julio de 2006.
} 
- Una forma específica de sentir el trabajo que brinda energía para la acción.

- Los valores sagrados o seculares que apuntan hacia la trascendencia de nuestros valores fundamentales.

- Los valores profundos que guían nuestra vida y nuestras prácticas en el trabajo.

- El reconocimiento de que los empleados poseen una vida interior que alimenta y es a la vez alimentada por un trabajo pleno de sentido en un contexto de comunidad.

- La manera particular de visualizar a los seres humanos en toda su riqueza, las relaciones de los seres humanos para alcanzar trascendencia, las relaciones entre seres humanos y la manera de alcanzar crecimiento personal.

Otros autores, en busca de una mayor claridad, señalan aspectos encontrados en organizaciones donde se promueve la espiritualidad en el trabajo tales como ética empresarial, verdad, creencia en Dios o en un poder superior, respeto, comprensión, apertura, honestidad, auto-motivación, fomento de la creatividad, el dar a los demás, confianza, amabilidad, orientación hacia equipos de trabajo, pocas barreras organizacionales, un sentido de paz y armonía, lugar de trabajo estéticamente agradable, interconexión, apoyo a la diversidad y aceptación (Journal of American Business. Cambridge: 2004). Según algunos, las palabras que mejor resumen la espiritualidad en el trabajo son interconexión, significado y realización personal (¿recuerdan a Maslow?).

Un artículo propone un plan en cuatro etapas para encarar el tema de la espiritualidad en una organización, a saber: a) conversaciones acerca del tema, si los empleados así lo quieren.
En tal caso, comenzar en forma suave y respetando los distintos puntos de vista; b) investigación acerca de los recursos disponibles, tales como conferencias, libros, oradores y grupos de discusión; c) fomento de un modo de trabajo para desarrollar la espiritualidad; esto puede ser un grupo de discusión, una actividad o un proyecto compartidos o una serie de oradores; $y$ d) evaluación de lo que funciona y lo que no para corregir esto último y apoyar lo primero. (Workforce. Costa Mesa: 2001).

¿Le conviene a las empresas adoptar estos programas? Según un especialista "las investigaciones sugieren que alentar la espiritualidad en el trabajo puede beneficiar aspectos tales como la creatividad, la honestidad y la confianza, el compromiso y la realización personal, todo lo cual en última instancia conduce a un mejor desempeño de la organización."

El tema de la espiritualidad en el trabajo es confuso y nebuloso y por esto quizás no se haya encarado en las organizaciones y en los medios académicos en forma amplia, profunda y sistemática, tal como lo señalan I. I. Mitroff y E. A, Denton en su artículo A Study of Spirituality in the Workplace (Sloan Management Review. Cambridge: verano de 1999).

Sin embargo, surge de una manera u otra. Lo pude comprobar en las numerosas ocasiones en que entrevisté a distintos gerentes en distintos países durante el transcurso de diversos trabajos de investigación. Salvo muy pocas excepciones, las personas entrevistadas siempre se mostraron muy dispuestas a brindarme la información solicitada. Me daba cuenta que no sólo se trataba de hablar de sus trabajos ?a todos nos gusta hacerlo? sino también de brindar información útil para jóvenes estudiantes. De este modo sus experiencias trascendían el hecho de haber trabajado para ganarse la vida y adquirían 
un significado más profundo al contribuir con su granito de arena a la formación y al desarrollo de futuras generaciones de gerentes.

Un ejemplo adicional quizás lo provea el Dr. Kim Clark, decano de la Harvard Business School hasta el 31 de julio de 2005. Según informó The Boston Globe (7 de junio de 2005) La decisión de Clark de aceptar el cargo de presidente de una pequeña escuela mormona en Idaho se debió a consideraciones personales y religiosas... Lawrence $\mathrm{H}$. Summers, el presidente de Harvard dijo que poco pudo hacer para retenerlo porque aceptó la profundidad de su compromiso religioso. "Tuve claro que, si bien soy el presidente de Harvard, quien había hablado había sido el presidente de la iglesia de Kim".

Después de todo, la posible contradicción señalada al principio parece no tener razón de ser. La espiritualidad en el trabajo exclama ¡presente! en el frío mundo real.

\section{Pregunta: ¿Hay alma en Su empresa?}

Al punto anterior no incluyó ninguna referencia a un tema relacionado, la existencia o no de «alma» (corporate soul) en la empresa, vuelto a mencionar con frecuencia a partir de la década de los 90. A juzgar por el número de libros en inglés que incluyen esta expresión en su título el tema atrae a muchos lectores. La palabra alma tiene varias acepciones en el Diccionario online de la Real Academia. Dos de éstas entiendo que son aplicables al tema que nos ocupa. Dicen así: "viveza, espíritu y energía" y "aquello que da espíritu, aliento y fuerza a algo".

¿Qué se entiende por alma en la empresa (corporate soul) o qué quieren decir los distintos autores cuando utilizan tal expresión? No es fácil contestar estos interrogantes en forma precisa. La idea detrás de la palabra ha evolucionado a lo largo de los años. R. S. Tedlow recuerda que luego de una decisión de 1886 de la justicia de los Estados Unidos donde se declaró que la corporación era una «persona» en lo referido a ciertos aspectos de la ley, los comentaristas observaron la ausencia de alma en la persona corporativa. Las grandes empresas respondieron que, por el contrario, sí estaba presente (Remembering Roland Marchand 1933-1997. Business History Review. Boston: primavera de 1998).

El Prof. Marchand, objeto del artículo recién mencionado, se ocupó del tema y de su relación con los esfuerzos de relaciones públicas de las grandes empresas en las décadas que van de fines del siglo XIX al término de la Segunda Guerra Mundial. Sus conclusiones señalaron que en los comienzos de este período éstas aspiraban a que se les reconociera un alma corporativa y que sus esfuerzos en este sentido fueron amplios, piadosos, poco concentrados y quijotescos. Al final del período, con sus proyectos de relaciones públicas en marcha, sus aspiraciones se dirigían a ser reconocidas como un buen vecino. Esto sugiere la posibilidad de que durante ese período los líderes de las grandes empresas o sus voceros no tuvieran en claro el lugar de las grandes empresas en la sociedad americana. 
Más cerca en el tiempo, algunos autores aclaran así los interrogantes que nos ocupan:

- El CEO debe establecer la visión de la empresa. Para esto es esencial desarrollar un alma empresaria que abarque los intangibles del espíritu humano que sienten las necesidades de otros por medio de aspectos como significado, propósito, empatía, cuidado y participación (L. E. Piper, Winning Loyalty with a Vision and a Corporate Soul. The Health Care Manager. Frederick: 2005)

- El alma organizacional pone en movimiento las posibilidades humanas más profundas y sagradas. Se manifiesta cuando las personas vuelcan creatividad, energía y pasión en el trabajo y viven su vida en forma plena. (J. Izzo y E. Klein, The Changing Values of Workers: Organizations Must Respond with Soul. The Healthcare Forum Journal. San Francisco: 1998)

- Un directivo explica el concepto de «alma» en el lugar de trabajo de la siguiente manera: "Hacer que la gente se ponga a hablar acerca del alma organizacional significa hacerlos hablar acerca de cómo empleados y gerentes se conectan unos con otros y con la persona que se beneficia con el trabajo realizado" (T. Brown, "Corporate Soul": Meaning Behind the Buzzwords. Harvard Management Update. 1998)

El autor citado en último término agrega que para Allan Cox, autor de Redefining Corporate Soul, "un número de gerentes más grande que nunca está tratando de convertir el lugar de trabajo en algo 'auténtico' para todos los involucrados -y la única manera de hacer que esto suceda es aumentando radicalmente el nivel de autoconocimiento de las personas y de la empresa".
No todos piensan de esta manera.

El historiador Thomas Frank quien, entre otros proyectos, estudiaba la historia de la literatura sobre el management, dijo lo siguiente en una entrevista publicada en septiembre de 2001 en la Harvard Business Review (Management Theory -or Theology?):

Me fascina la teoría del management porque siempre pienso acerca de quién la lee y por qué. Se supone que el mundo de los negocios es la parte más práctica de la vida americana y una que no deja mucho lugar a los pensamientos ampulosos. Sin embargo, lo que leen los gerentes es fantasioso y desconectado de la realidad. Hoy día muy pocos libros entran en la categoría de lo que llamo Taylorismo, donde incluyo los que tratan acerca de cómo hacer más racionales y eficientes los negocios y sus procesos. Reengineering the Corporation (J Champy y M. Hammer) fue el que más se acercó a esto en la última década y aun en este caso sus autores hicieron un gran esfuerzo para distanciarse de la tradición Taylorista. Esta corriente prácticamente desapareció y todo lo que se ve ahora es ese material que mira el ombligo (navel-gazing stuff) referido al cambio y a la gente que medita sobre si la empresa tiene alma o no.

Hoy día nuestros conciudadanos trabajan más fuerte que nunca. Si uno le va a dedicar su vida a una empresa, mejor que sea algo especial. Por esto la empresa debe ser descripta como algo más grande que una persona, como algo que tiene sentimientos y nos sobrevive, que tiene valores, que tiene marcas trascendentes, que tiene un alma. Por esta razón los gerentes duros y prácticos leen este material increíblemente suave. Quienes leen libros sobre el alma de las empresas no buscan consejos prácticos. Lo que buscan es reafirmar su fe. 
La opinión anterior implica, de alguna manera, que muchos en las grandes corporaciones se hallan aún hoy a la búsqueda de «legitimidad».
¿Estamos en presencia de un debate? ¿O es sólo la voz de un historiador?

Lector o lectora: ¿hay alma en su empresa?

\section{EMPRESAS FAITH-FRIENDLY. (LA RELIGIÓN EN EL LUGAR DE TRABAJO)}

No hace falta ser una persona muy informada para saber que la religión forma parte de importantes conflictos internacionales de la actualidad. Tampoco hace falta ser un experto politólogo para observar que la religión se expresa hoy día con fuerza cuando se discuten ciertos temas que hacen a la vida política de los distintos países. La revista Time, por ejemplo, en su edición de los primeros días de febrero de 2007 dice que "esta vez, los precandidatos (a suceder a George W. Bush) de ambos partidos están buscando el tono adecuado para referirse a la religión".

\section{¿Qué sucede con la religión en el seno de las empresas de los Estados Unidos?}

Desde los años 60 y por espacio de varias décadas el énfasis estuvo puesto, como uno de los resultados de las leyes de Igualdad de Oportunidades (Equal Employment Opportunity), en el derecho de los trabajadores a solicitar una adaptación de sus condiciones de trabajo para poder practicar su religión fuera de la empresa.

A partir de los 90 la situación comenzó a cambiar. Las razones que se citan incluyen, entre otras, la globalización, los cambios frecuentes de la tecnología, la reingeniería y el downsizing y la consiguiente pérdida de puestos de trabajo, todo lo cual indujo a muchos trabajadores a replantear su vida ${ }^{1}$. Luego, en los años siguientes, se agregaron los acontecimientos del 11 de septiembre y sus consecuencias, una mayor diversidad religiosa en la fuerza de trabajo y el paso de los años para la generación de los baby-boomers.

La llegada de la religión al lugar de trabajo ?algo que hasta no hace muchos años se suponía no debía traspasar la puerta de entrada de las empresas? se manifiesta cada vez más. Por ejemplo:

a. Capellanes de empresas (corporate chaplains). "Los capellanes de empresas han sido contratados desde hace mucho tiempo por empresas del sur y del oeste del país; pero ahora el fenómeno está en expansión a medida que las empresas agregan capellanes y las integradas por capellanes llevan a cabo adquisiciones. Un dirigente religioso opina que la utilización de capellanes en las empresas de los Estados Unidos crece a una tasa del 10 por ciento anual". (E. Tahmincioglu, Face of Employee Assistance is Often a Company Chaplain. The New York Times. Nueva York: 4 de enero de 2004);

b. Desayunos de oraciones (prayer breakfasts). "Los desayunos de oraciones se han hecho populares en la actualidad entre los ejecutivos de sectores donde se suponía no habrían de llegar como ser tecnología y propiedades inmuebles". (Toppling a Taboo: Business Go "FaithFriendly". Knowledge@Wharton, 24 de enero de 2007); y 
c. Grupos religiosos (religious network groups). "Hasta hace algunos unos años, nadie podía haber pronosticado la explosión de intereses espirituales en una comunidad empresaria que se suponía secular. Sin embargo, en la actualidad la formación de redes o grupos religiosos es una de las muchas maneras por medio de las cuales los hombres de negocios tratan de recuperar en sus vidas un sentido de equilibrio $y$ dirección". (Laura Nash, What policy should GenCorp adopt toward religious network groups? Harvard Business Review: Boston: julio-agosto de 1999).

Las adaptaciones solicitadas por los trabajadores en el tema de la religión en el trabajo se refieren habitualmente a cambios de horarios, a actividades de proselitismo entre los compañeros de trabajo, a vestimenta exigida por determinada religión y a expresión religiosa, cómo hacer la exhibición de materiales religiosos y la posibilidad de rezar, estudiar o discutir en el tiempo de descanso ?todos temas delicados que requieren el cumplimiento de normas legales para disminuir la posibilidad de litigios.

El cumplir con dichas normas no es tarea sencilla. Siempre está latente el riesgo de que una o más personas invoquen la existencia de acoso religioso o discriminación religiosa en la organización. La ley señala que si el empleado es sincero en sus creencias religiosas, el empleador está obligado, si el empleado presenta un pedido, a una adaptación razonable que no le implique un esfuerzo fuera de lo normal (undue hardship). Obviamente,"sincero, razonable y fuera de lo normal requieren sus respectivas aclaraciones y un conocimiento de la jurisprudencia.
Por ejemplo: "la autorización referida a cubrirse la cabeza, vestir un manto (robe), dejarse la barba o el pelo largo, pintarse la cara o exhibir insignias o símbolos por motivos religiosos, aun cuando esto implique una desviación de las normas prescriptas por la empresa o no cumpla con las expectativas del resto de los trabajadores. Si lo anterior implica riesgos a la seguridad ?como sería el caso de un trabajador que, al vestir tal manto, corra el riesgo de que se le enganche en la máquina alrededor de la cual trabaja? el empleador tiene el derecho a una prohibición si evitar tales riesgos implica un costo importante". (W. Atkinson, Divine Acommodations: Religion in the Workplace. Risk Management. Nueva York: octubre de 2000).

Quienes propician la presencia de la religión en el lugar de trabajo señalan que la empresa debe entrenar a sus supervisores en lo relativo a los derechos religiosos de los trabajadores. Agregan que esto le permitirá a la empresa contar, en el caso de los empleados religiosos, con personal más contento, más productivo, con una moral a un nivel más alto, que se queda más tiempo y que colabora más que los trabajadores que no sienten que deban traer sus escalas de valores al trabajo.

La adaptación de las empresas a las distintas prácticas religiosas puede tomar distintos matices y formas, a veces inesperados. Hace unos años, una persona muy experimentada, a punto de incorporarse a una empresa latinoamericana para ocupar un importante cargo gerencial, le informó a quien pronto iba a ser su jefe que su religión le impedía trabajar los días sábado. "No tengo ningún inconveniente" le contestó éste. "Puede trabajar los días domingo".

${ }^{1}$ Ver artículo No. 84 La Espiritualidad en el Trabajo en www.guillermoedelberg.com.ar 